\title{
Validation of atmospheric correction algorithm ATCOR
}

\author{
Bringfried Pflug ${ }^{*}$, Magdalena Main-Knorn ${ }^{\mathrm{a}}$ \\ ${ }^{a}$ German Aerospace Center, Remote Sensing Technology Institute, \\ Rutherfordstrasse 2, 12489 Berlin, Germany
}

\begin{abstract}
Atmospheric correction of satellite images is necessary for many applications of remote sensing, i.e. computation of vegetation indices and biomass estimation. The largest uncertainty in atmospheric correction arises out of spatial and temporal variation of aerosol amount and type. Therefore validation of aerosol estimation is one important step in validation of atmospheric correction algorithms.

Our ground-based measurements of aerosol-optical thickness spectra (AOT) were performed synchronously to overpasses of satellites Rapid-Eye and Landsat. Validation of aerosol retrieval by the widely used atmospheric correction tool ATCOR ${ }^{1,2}$ was then realized by comparison of AOT derived from satellite data with the ground-truths.

Mean uncertainty is $\triangle$ AOT550 $\approx 0.04$, corresponding approximately to uncertainty in surface albedo of $\Delta \rho \approx 0.004$. Generally, ATCOR-derived AOT values are mostly overestimated when compared to the ground-truth measurements. Very little differences are found between Rapid-Eye and Landsat sensors. Differences between using rural and maritime aerosols are negligible within the visible spectral range.
\end{abstract}

Keywords: Atmospheric correction, ATCOR, validation, aerosols, Rapid-Eye, Landsat

\section{INTRODUCTION}

Atmospheric correction of satellite data is required for many applications of remote sensing, like computation of vegetation indices, biomass estimation and plant health studies. It reduces effects of scattering and absorption by gases and aerosols in the atmosphere between the Earth's surface and the sensor and minimizes the influence of solar illumination and topography on the registered signal. However, application of atmospheric correction algorithms requires knowledge about the uncertainty of the correction process. This study provides an estimation of atmospheric correction uncertainty for ATCOR ${ }^{1.2}$ using ground-based measurements. ATCOR is a widely used tool for atmospheric correction of satellite data. We used Rapid-Eye and Landsat satellite data for comparative exercise.

Table 1. Variation of atmospheric absorption and scattering within Rapid-Eye spectral channels. Given are the optical thickness due to absorption of $\mathrm{H} 2 \mathrm{O}$ and $\mathrm{O} 3$ and the optical thickness for molecular $\left(\tau^{\mathrm{M}}\right)$ and aerosol scattering $\left(\tau^{\mathrm{A}}\right)$.

\begin{tabular}{|c|c|c|c|c|c|c|}
\hline & & Blue & Green & Red & RedEdge & NIR \\
\hline \multirow{2}{*}{$\mathrm{H} 2 \mathrm{O}$} & maximum variation & 0.001 & 0.002 & 0.004 & 0.045 & 0.024 \\
& typical variation & 0.000 & 0.001 & 0.002 & 0.024 & 0.013 \\
\hline $\mathrm{O} 3$ & typical variation & 0.001 & 0.004 & 0.002 & 0.001 & 0.000 \\
\hline$\tau^{\mathrm{M}}$ & $\Delta \rho= \pm 15 \mathrm{hPa}$ & 0.003 & 0.001 & 0.001 & 0.001 & 0.000 \\
\hline \multirow{2}{*}{$\tau^{\mathrm{A}}$} & maximum variation $^{2011}$ & 0.38 & 0.35 & 0.34 & 0.30 & 0.28 \\
& typical variation $^{2011}$ & 0.11 & 0.10 & 0.09 & 0.07 & 0.06 \\
\hline
\end{tabular}

*bringfried.pflug@dlr.de; phone +49 (30) 67055 - 655; fax +49 (30) 67055 - 642

Remote Sensing of Clouds and the Atmosphere XIX; and Optics in Atmospheric Propagation and Adaptive Systems XVII, edited by Adolfo Comerón, Evgueni I. Kassianov, Klaus Schäfer, Richard H. Picard, Karin Stein, John D. Gonglewski, Proc. of SPIE Vol. 9242, 92420W · (C) 2014 SPIE · CCC code: 0277-786X/14/\$18 · doi: 10.1117/12.2067435 
Atmospheric correction includes correction of molecular absorption, molecular scattering and aerosol effects. The relative importance of these processes is depicted in table 1 on the example of Rapid-Eye spectral channels. We found, that spectral channels of Landsat give equivalent results. Given are the optical thickness of water vapor and ozone absorption, and the optical thickness of scattering on molecules and aerosol particles. Absorption features are computed on basis of MODTRAN4 ${ }^{3}$. Maximum variation refers to the difference between absorber amounts in the tropical (most humid) and subarctic winter (most dry) atmospheres. The tropical atmosphere has lower ozone content compared to the subarctic atmosphere. The amounts of typical variations are taken from the ATCOR manual ${ }^{4}$. Optical thickness $\tau^{\mathrm{M}}$ depends on air pressure, and realistic variations of $\tau^{\mathrm{M}}$ are estimated for pressure variation of $\pm 15 \mathrm{hPa}$. Aerosol variations are estimated from own observations in 2011 on 16 separate days. The maximum observed AOT is set to the maximum variation of AOT, because in clear atmospheres AOT near zero is possible. The Root Mean Square (RMS) of the AOT observations is taken as typical variation. Table 1 reveals that both optical thickness of molecular scattering and absorption are lower than the maximum variation of AOT in 2011 by about an order of magnitude. The largest uncertainties for atmospheric correction procedures arise out of aerosol correction due to spatial and temporal variation of aerosol amount and type. Therefore, we investigate the uncertainty of atmospheric correction by validation of aerosol estimation. Kaufman et.al. ${ }^{5}$ showed, that an uncertainty in aerosol retrieval $\Delta \tau^{\mathrm{A}}$ is linked to an uncertainty in surface reflectance $\Delta \rho$ by the relation of:

$$
\Delta \rho=\Delta \tau^{\mathrm{A}} / 10 .
$$

In this study we make use of free available and frequently used satellite data and widely known tools for their preprocessing to provide first experimental estimates of uncertainty in AOT retrieval and thus surface reflectance calculation. Our findings may help to recognize the influence and assess the effects of atmospheric correction uncertainty for multispectral high (Rapid-Eye) and medium (Landsat) spatial resolution data for environmental applications.

\section{DATA}

The proposed validation of atmospheric correction requires ground-based measurements of vertical column AOT-spectra synchronously to satellite overpasses. Validation is performed by direct comparison of aerosol retrieval from ATCOR with ground-based results. Ground-based aerosol measurements were acquired during 14 days synchronously to overpasses of Rapid-Eye, Landsat 5, Landsat 7 and Landsat 8 between 2001 and 2013. Test sites are located in Germany and at the Polish Baltic Sea coast (See Fig. 1) and can be characterized by flat terrain with dense dark vegetation pixels existing in the images.

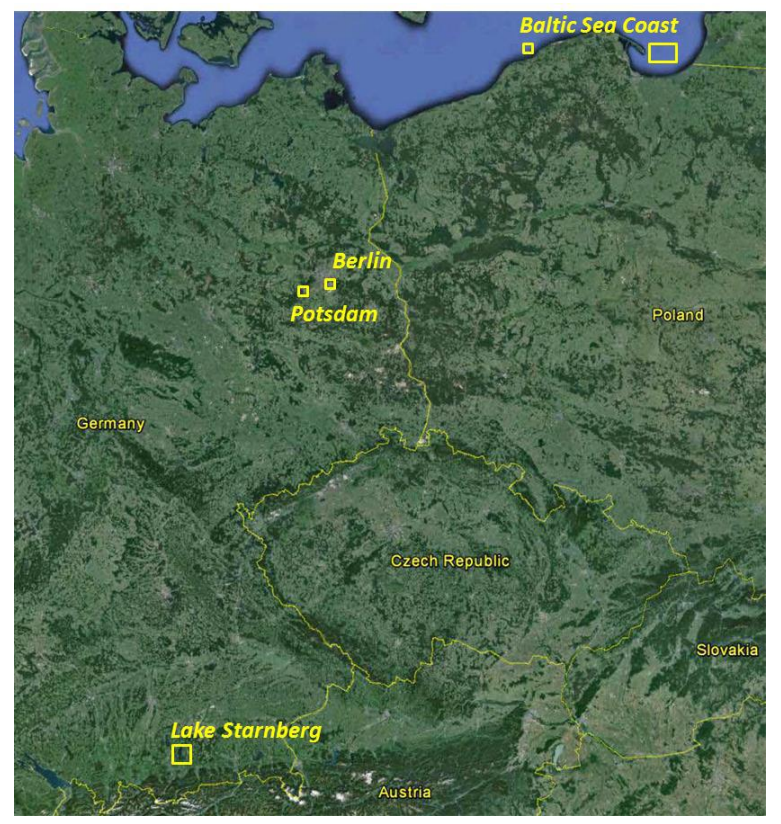

Figure 1. Test sites (location of sunphotometer (ground-truth) measurements) 


\subsection{Satellite images}

Table 2 gives an overview over the satellite images synchronous to available ground-based data. Selection of satellite data was limited to images with less than or equal $2 / 8$ cloudiness. While most overpasses are exactly synchronous to ground-based measurements, some have time differences up to $2.5 \mathrm{~h}$. Even with this time difference the ground-based measurements can be assumed to be valid for the overpass.

Table 2. Satellite images synchronously to available aerosol ground-truth (gt) data. Times are given in UTC.

\begin{tabular}{|c|c|c|c|c|c|}
\hline Date & Test site & Satellite & $\begin{array}{c}\text { Satellite } \\
\text { overpass } \\
\text { time }\end{array}$ & $\begin{array}{l}\text { Time of gt- } \\
\text { measurement }\end{array}$ & comment \\
\hline 2001-05-08 & $\begin{array}{l}\text { SE Baltic Sea, } \\
\text { Bay of Gdank }\end{array}$ & Landsat 7 ETM+ & $09: 33$ & $06: 30$ to $12: 00$ & Cloudless, Wind NNW \\
\hline $2003-05-30$ & $\begin{array}{l}\text { SE Baltic Sea, } \\
\text { Bay of Gdank }\end{array}$ & Landsat 7 ETM+ & $09: 32$ & $06: 05$ to $15: 45$ & $2 / 8$ cloudiness, Wind $\mathrm{SE}$ \\
\hline 2005-10-01 & $\begin{array}{c}\text { SE Baltic Sea, } \\
\text { Łeba }\end{array}$ & Landsat 7 ETM+ & $09: 38$ & $09: 10$ to $12: 10$ & $1 / 8$ cloudiness, Wind $S$ \\
\hline 2006-09-26 & $\begin{array}{c}\text { SE Baltic Sea, } \\
\text { Ustka }\end{array}$ & Landsat $5 \mathrm{TM}$ & $09: 43$ & $11: 45$ to $12: 10$ & Cloudless, Wind SE \\
\hline 2011-03-01 & Potsdam & Rapid-Eye & $10: 09$ & $11: 40$ to $11: 45$ & Cloudless \\
\hline 2011-04-20 & Potsdam & Rapid-Eye & $10: 15$ & $12: 55$ to $13: 00$ & Cloudless \\
\hline 2011-09-06 & Potsdam & $\begin{array}{c}\text { Landsat } 5 \text { TM } \\
\text { Rapid-Eye }\end{array}$ & $\begin{array}{l}09: 51 \\
10: 13\end{array}$ & $10: 30$ to $13: 00$ & $2 / 8$ cloudiness \\
\hline 2011-10-13 & Potsdam & Rapid-Eye & $10: 09$ & $10: 10$ to $10: 20$ & $2 / 8$ cloudiness \\
\hline 2011-11-08 & Potsdam & Rapid-Eye & $10: 15$ & $08: 15$ to $14: 30$ & Cloudless \\
\hline 2012-05-14 & Lake Starnberg & Rapid-Eye & $10: 23$ & 06:30 tp 13:00 & $2 / 8$ cloudiness \\
\hline 2012-08-14 & Lake Starnberg & Rapid-Eye & $10: 11$ & $6: 15$ to $09: 00$ & $2 / 8$ cloudiness \\
\hline $2013-05-15$ & Berlin & Landsat 8 OLI & $09: 58$ & $10: 30$ to $13: 00$ & Cloudless \\
\hline 2013-07-09 & Potsdam & Landsat 8 OLI & $10: 04$ & 08:40 to $16: 00$ & $2 / 8$ cloudiness \\
\hline $2013-08-02$ & Potsdam & Landsat 7 ETM+ & $09: 58$ & $08: 45$ to $10: 45$ & cloudless \\
\hline
\end{tabular}

\subsection{Ground based sunphotometer measurements}

Ground-based measurements were performed with 2 Microtops II Instruments: a Ozonometer and a sunphotometer. Both instruments have a view angle of $2.5^{\circ}$. Channel specifications are given in table 3 . Radiation captured by collimators and bandpass filters radiates onto the photodiodes. Silicon photodetectors are used for the visible and near infrared (NIR) channels. In the first three channels GaP photodetectors (Gallium Phosphate) are used due to their sensitivity in the UV region, low noise level and low sensitivity above $500 \mathrm{~nm}$. Signals from the photodiodes are processed in series with 20 conversions per second so that results can be treated as if the photodiodes were read simultaneously.

Measurements are performed at each time with both instruments in a close sequence; first few scans with one Microtops and immediately afterward few scans with the other. Thus, the data characterize the atmosphere at the same time and can be analyzed coupled. Measuring multiple scans with each instrument allows excluding some scans with imperfect orientation to the sun. 
Table 3. Characteristics of ozonometer and sunphotometer.

\begin{tabular}{|rl|lll|}
\hline \multicolumn{2}{|c|}{ Optical channels Ozonometer } & \multicolumn{3}{c|}{ Optical channels Sunphotmeter } \\
\hline $305.5 \pm 0,3 \mathrm{~nm}$ & FWHM 2,0 nm & $380 \pm 0,4 \mathrm{~nm}$ & FWHM $4 \mathrm{~nm}$ \\
$312.5 \pm 0,3 \mathrm{~nm}$ & FWHM 2,0 nm & $440 \pm 1,5 \mathrm{~nm}$ & FWHM $10 \mathrm{~nm}$ \\
$320.0 \pm 0,3 \mathrm{~nm}$ & FWHM 2,0 nm & $500 \pm 1,5 \mathrm{~nm}$ & FWHM $10 \mathrm{~nm}$ \\
$936 \pm 1,5 \mathrm{~nm}$ & FWHM $10 \mathrm{~nm}$ & $675 \pm 1,5 \mathrm{~nm}$ & FWHM $10 \mathrm{~nm}$ \\
$1020 \pm 1,5 \mathrm{~nm}$ & FWHM $10 \mathrm{~nm}$ & $870 \pm 1,5 \mathrm{~nm}$ & FWHM $10 \mathrm{~nm}$ \\
\hline
\end{tabular}

\section{DATA PROCESSING}

\subsection{Processing of satellite data}

Atmospheric correction module ATCOR2 (software version 8.2.1) for flat terrain conditions was used for processing satellite data. Adjustable parameters had been set to variable visibility over the scene, rural aerosol type, range of adjacency effect of $1 \mathrm{~km}$, and number of adjacency zones of 1 .

Selection of rural aerosol type is reasonable for the satellite images under consideration. Only one date of measurements and satellite overpass at the Baltic Sea coast was characterized by wind direction coming from the sea. Nevertheless, we tested three of the four aerosol type models available in ATCOR: maritime, rural, and urban (aerosol model for desert condition is not representative for our test sites). Processing with maritime and rural aerosol models give nearly identical results in the visible/NIR. Urban aerosol type gives very different results which less agree with the ground-truth data.

There are two different algorithms implemented within ATCOR for Landsat and Rapid-Eye data correction. The algorithm for Landsat data is similar to that published by Kaufman ${ }^{5}$ for processing of MODIS data. Landsat data have a spectral channel around $2.2 \mu \mathrm{m}$, which can be easily used for detection of dense dark vegetation pixels (DDV). The influence of aerosols can be neglected at $2.2 \mu \mathrm{m}$ and the signal measured at satellite can be interpreted as surface reflectance. A correlation of reflectance of DDV-pixels between the shortwave infrared (SWIR) and the red band is used for aerosol retrieval. Rapid-Eye data cannot be processed with that algorithm, because the sensor doesn't have a SWIR channel. The algorithm applied for sensors like Rapid-Eye uses multiple thresholds for determination of DDV-pixels in the red part of the spectrum ${ }^{2}$.

ATCOR uses a parameter called Visibility (VIS) for characterization of vertical column aerosol-optical thickness (AOT), calculated as follows:

$$
\operatorname{AOT550}=\exp (a(z)+b(z) \cdot \ln (V I S))
$$

with $\mathrm{a}=1.54641$ and $\mathrm{b}=-0.854022$ at $\mathrm{z}=0 \mathrm{~km}$ serves for conversion of VIS to AOT (see table 4 ).

\subsection{Algorithm for processing sunphotometer measurements}

Sunphotometer measurements are processed using a coupled analysis of sunphotometer and ozonometer measurements ${ }^{6}$ Examples of the outputs are shown in figure 2. First ozonometer data are used for computation of vertical column ozone content [cmSTP]. Actual vertical column ozone content is necessary for computation of vertical column AOT-spectra. AOT spectra allow computation of the vertical column Ångstrœm exponent $\alpha$, which contains information about aerosol particle size respectively aerosol type. Spectral dependency of AOT given with the AOT-spectra is also used for computation of vertical column water vapor content [ $\mathrm{cm}$ precipitable water column] and for interpolating the AOT at $550 \mathrm{~nm}$. Finally, equation (2) can be used for conversion of AOT550 to VIS. 
Table 4. Conversion between ATCOR parameter VIS and aerosol-optical thickness AOT.

\begin{tabular}{|c|c|}
\hline AOT550 & VIS \\
\hline 0.05 & $204 \mathrm{~km}$ \\
\hline 0.10 & $91 \mathrm{~km}$ \\
\hline 0.15 & $56 \mathrm{~km}$ \\
\hline 0.20 & $40 \mathrm{~km}$ \\
\hline 0.25 & $31 \mathrm{~km}$ \\
\hline 0.30 & $25 \mathrm{~km}$ \\
\hline 0.35 & $21 \mathrm{~km}$ \\
\hline 0.40 & $18 \mathrm{~km}$ \\
\hline 0.45 & $16 \mathrm{~km}$ \\
\hline 0.50 & $14 \mathrm{~km}$ \\
\hline
\end{tabular}

\section{RESULTS AND DISCUSSION}

\subsection{Results of sunphotometer measurements}

The entire dataset contains both, situations with very low and with high vertical column aerosol content (see table 5). Except the first date, all dates indicate presence of small aerosol particles, probably of continental origin. For the first dataset at the Baltic Sea coast the calculated Ångstrœm-Exponent is typical for maritime aerosols, what is consistent with the wind direction coming from the sea at this day.
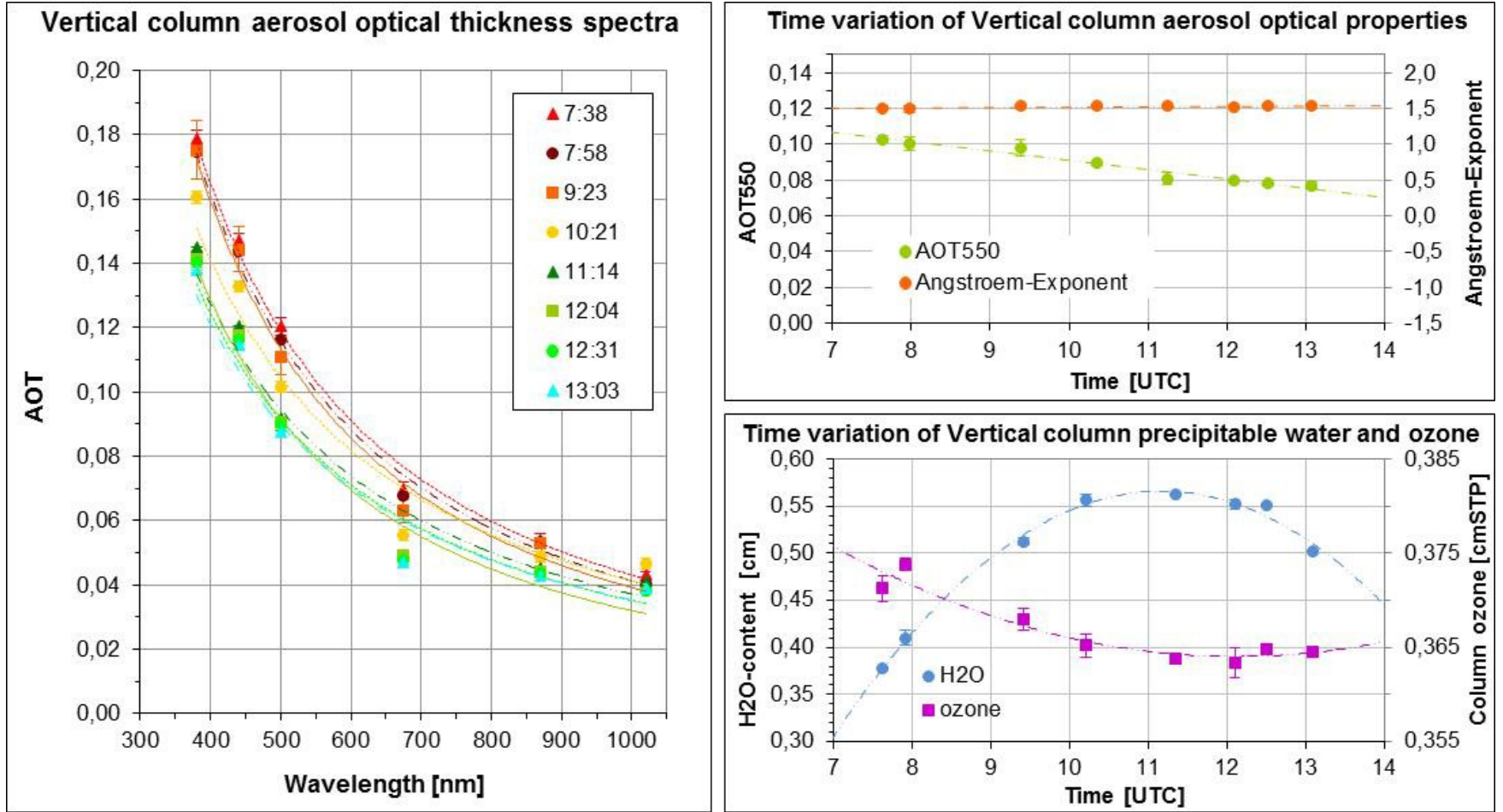

Figure 2. Example of sunphotometer-outputs for Rapid-Eye overpass at 14.05.2012, 10:23 UTC 
Table 5. Ground-based data synchronous to satellite overpasses.

\begin{tabular}{|c|c|c|c|c|c|}
\hline Date & Location & $\begin{array}{c}\text { measurement } \\
\text { time [UTC] }\end{array}$ & AOT550 & VIS & $\begin{array}{c}\text { Ånstræm- } \\
\text { Exponent }\end{array}$ \\
\hline 08.05 .2001 & Bay of Gdansk & $09: 45$ & $0.046 \pm 0.003$ & $225 \pm 20 \mathrm{~km}$ & 0.7 \\
\hline 30.05 .2003 & Bay of Gdansk & $09: 00$ & $0.138 \pm 0.005$ & $62 \pm 3 \mathrm{~km}$ & 1.2 \\
\hline 01.10 .2005 & Łeba & $09: 20$ & $0.038 \pm 0.002$ & $285 \pm 20 \mathrm{~km}$ & 1.8 \\
\hline 26.09 .2006 & Ustka & $12: 00$ & $0.136 \pm 0.003$ & $64 \pm 2 \mathrm{~km}$ & 1.4 \\
\hline 01.03 .2011 & Potsdam & $11: 45$ & $0.145 \pm 0.001$ & $58 \pm 0.5 \mathrm{~km}$ & 1.4 \\
\hline 20.04 .2011 & Potsdam & $13: 00$ & $0.279 \pm 0.000$ & $27 \pm 0 \mathrm{~km}$ & 1.7 \\
\hline 06.09 .2011 & Potsdam & $09: 15$ & $0.077 \pm 0.002$ & $123 \pm 4 \mathrm{~km}$ & 1.0 \\
\hline 13.10 .2011 & Potsdam & $10: 15$ & $0.063 \pm 0.002$ & $155 \pm 5 \mathrm{~km}$ & 1.0 \\
\hline 08.11 .2011 & Potsdam & $10: 10$ & $0.324 \pm 0.003$ & $23 \pm 0.5 \mathrm{~km}$ & 1.2 \\
\hline 14.05 .2012 & Lake Starnberg & $10: 20$ & $0.085 \pm 0.001$ & $100 \pm 2 \mathrm{~km}$ & 1.6 \\
\hline 14.08 .2012 & Lake Starnberg & $09: 00$ & $0.155 \pm 0.009$ & $49 \pm 4 \mathrm{~km}$ & 1.8 \\
\hline 15.05 .2013 & Berlin & $10: 10$ & $0.073 \pm 0.005$ & $130 \pm 12 \mathrm{~km}$ & 1.4 \\
\hline 09.07 .2013 & Potsdam & $10: 00$ & $0.125 \pm 0.000$ & $50 \pm 1 \mathrm{~km}$ & 1.5 \\
\hline 02.08 .2013 & Potsdam & $10: 00$ & $0.073 \pm 0.002$ & $129 \pm 5 \mathrm{~km}$ & 1.5 \\
\hline
\end{tabular}

\subsection{Comparison of ATCOR results with ground-truths}

Figure 3 shows the comparison of AOT550 retrieved with ATCOR from satellite data with ground-truth values. The left plot contains the mean over $3 \times 3$ Landsat pixels respectively the mean over $5 \times 5$ Rapid-Eye pixels around the location of sunphotometer measurements. The right plot illustrates the mean over all land pixels of the whole scene. Both plots look similar. AOT-retrievals of ATCOR agree very satisfying with ground-truth data. Mean AOT difference between ATCOR and ground-truth is 0.04 for both plots; the maximum observed AOT difference is 0.1 . The linear fit through all data points shows that ATCOR mostly overestimates the atmospheric turbidity. The largest differences are observed in clear atmospheres with low AOT. Following equation (1) the difference in AOT of $\Delta \tau^{\mathrm{A}}=0.04$ corresponds to uncertainty in surface reflectance of $\Delta \rho=0.004$. To get an idea, what does this uncertainty mean for applications, it is compared to the requirements of the German EnMAP mission. Requirements for processing EnMAP data are $\Delta \tau^{\mathrm{A}}<0.06$ and $\Delta \rho<0.01$. Both are complied with the results of the present study for the investigated area and the small number of synchronous overpasses.

The most noticeable differences between both plots in figure 3 are the larger vertical error bars in the right plot. This is clearly caused by the variation of AOT over full scenes. At least for Rapid-Eye tiles the AOT-variation over the image is much smaller than the difference to the ground-truth. This leads to the conclusion that single Rapid-Eye tiles can be processed with a fixed AOT (fixed VIS).

Scene selection was limited to conditions with cloud cover less or equal 2/8. Cloudless scenes are marked in figure 3 with unfilled data points and data points with some clouds present in the images are filled. There are no remarkable differences in the processing results for cloudless and little cloudy images. Aerosol retrieval in ATCOR provides accurate results even with some clouds present in the satellite image.

Unfortunately, there is only one example of dataset with images from 2 overpassing satellites at the same day, time and test site (September 6, 2011). Processing the Landsat 5 image and the Rapid-Eye tile for this day gave identical results in the vicinity of the location of sunphotometer measurements. Mean AOT values over full images were not compared due to high cloud contamination over the Rapid-Eye tile. 

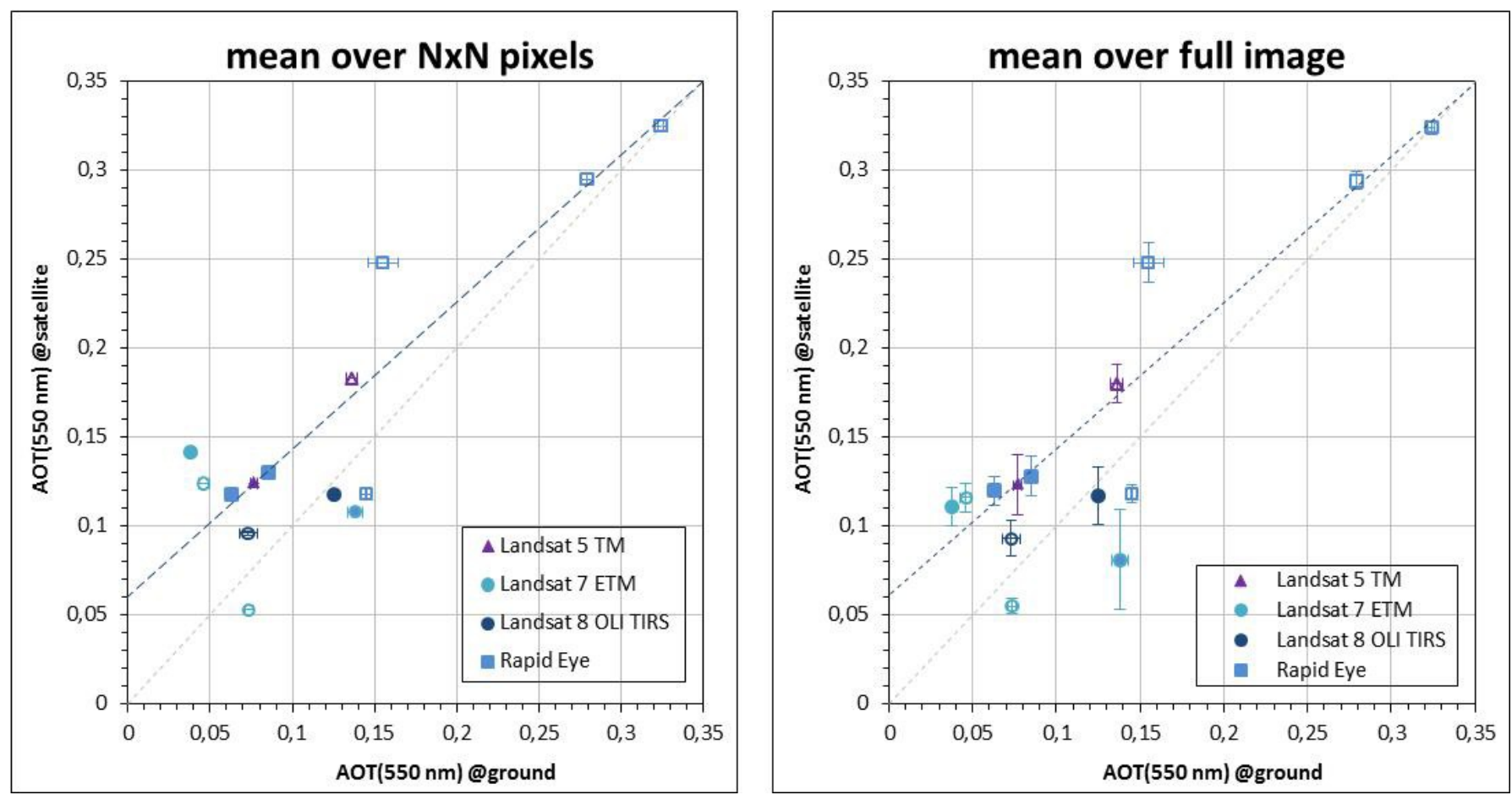

Figure 3. Comparison of AOT550 retrieved with ATCOR from satellite data with ground-truth values. Left plot: mean over $3 \times 3$ Landsat pixels respectively mean over $5 \times 5$ Rapid-Eye pixels around the location of sunphotometer measurements. Right plot: mean over all land pixels of the whole scene. Unfilled data points: cloudless images. Filled data point: Images with less or equal $2 / 8$ cloudiness. The dark line gives the trend through all data points.

Landsat and Rapid-Eye data were processed with different algorithms within ATCOR. Comparing results for Landsat and Rapid-Eye scenes shows no significant differences. Mean difference between ATCOR retrieval and ground-truth AOT is 0.04 for both kinds of sensors and maximum differences are 0.09 and 0.10 respectively. Both algorithms implemented in ATCOR for different sensors provide accurate and comparable results.

The applied dataset is too small for performing reliable statistical analysis. Nevertheless trying to derive a ranking of sensors revealed Landsat 8 OLI to perform better than Rapid-Eye, followed then by Landsat 5 TM and Landsat 7 ETM. The total dataset contains two Landsat 8 OLI overpasses giving mean difference of 0.02 between ATCOR-AOT and ground-truth. Six Rapid-Eye tiles give mean difference of 0.04, two Landsat 5 images perform with mean difference of 0.05 , and finally four Landsat 7 images reveal mean difference of 0.06 .

\section{SUMMARY AND CONCLUSIONS}

Atmospheric correction algorithm ATCOR was validated on the level of aerosol retrieval uncertainties for test sites in middle Europe. ATCOR has shown a very nice performance. Rural aerosol type can be selected for processing satellite images in the region under investigation. Mean uncertainties of aerosol retrieval with ATCOR are $\triangle$ AOT550 $\approx 0.04$ corresponding approximately to surface reflectance uncertainty $\Delta \rho \approx 0.004$. Mostly ATCOR overestimates the atmospheric turbidity. Landsat and Rapid-Eye data are processed with different algorithms within ATCOR. Both algorithms are working precise and comparable. Aerosol retrieval in ATCOR provides accurate results even with some clouds present in the satellite image. More satellite overpasses synchronous to atmospheric ground-truth measurements would allow performing a more detailed and reliable statistical analysis.

The present study is limited to validation of aerosol estimation, which is an important part for validation of atmospheric correction. Additional studies to validate surface reflectance and other processes and effects in atmospheric correction are required and forthcoming. One common approach would consist in running a Radiative Transfer Model with ground-based AOT and water vapor data as inputs ${ }^{8}$. The result of the model computation is then used as the (true) reference of surface reflectance and compared with the surface reflectance retrieved from an atmospheric correction processor. 


\section{ACKNOWLEDGEMENT}

We sincerely thank BlackBridge AG for providing data from the Rapid-Eye Science Archive (RESA). We thank Tymon Zielinski from the IOPAS for assistance organizing the measurements at the Polish Baltic Sea Coast and we thank Helge Witt for performing some of the Microtops measurements.

\section{REFERENCES}

[1] Richter, R., "A spatially adaptive fast atmospheric correction algorithm", International Journal of Remote Sensing 17(6), 1201-1214 (1996); http://dx.doi.org/10.1080/01431169608949077

[2] Richter, R., Schläpfer, D. and Müller, A., "An automatic atmospheric correction algorithm for visible / NIR imagery", International Journal of Remote Sensing 27(10), 2077-2085 (2006); doi:10.1080/01431160500486690

[3] Berk, A., Anderson, G. P., Acharya, P. K., Hoke, M. L., Chetwynd, J. H., Bernstein, L. S., Shettle, E. P., Matthew, M. W. and Adler-Golden, S.M., [MODTRAN4 Version 3, Revision 1, User's Manual], Air Force Research Laboratory, Hanscom AFB, Bedford, MA, U.S.A., (2003)

[4] Richter, R., [Atmospheric / Topographic Correction for Satellite Imagery, (ATCOR-2/3 User Guide, Version 8.0, April 2011], DLR - German Aerospace Center, (2011),

[5] Kaufman, Y. J., Wald, A. E., Remer, L.A., Gao, BC., Li, RR. and Flynn, L., "The MODIS 2,1- $\mu$ m ChannelCorrelation with Visible Reflectance for Use in Remote Sensing of Aerosol", IEEE Transactions on Geoscience and Remote Sensing 35(5), 1286-1298 (1997)

[6] Pflug, B., "Ground based measurements of aerosol properties using Microtops instruments", AIP Conf. Proc. 1531, 588-591 (2013); doi: 10.1063/1.4804838, View online: http://dx.doi.org/10.1063/1.4804838

[7] v. Bargen, A., Grosser, J., [Environmental Mapping \& Analysis Program (EnMAP), Ground Segment Requirements Document], GRD, EN-DLR-RS-006 (2010)

[8] Ju, J., Roy, D. P., Vermote, E., Masek, J. and Kovalskyy, V., "Continental-scale validation of MODIS-based and LEDAPS ETM+ Atmospheric correction methods", Remote Sens. Environ. 122(SI), 175-184 (2012) 